\title{
Hypertrichosis in children after immobilization with plaster of Paris
}

\author{
Yakdhan Z. Alsaleem \\ From the Department of Surgery, College of Medicine, University of Mosul. \\ Correspondence: Yakdhan Z. Alsaleem. Lecturer, Department of Surgery, College of Medicine, University of Mosul, Mosul, \\ Iraq. Email: alsaleem_y@yahoo.com.
}

(Ann Coll Med Mosul 2013; 39 (1): 80-83).

Received: $20^{\text {th }}$ Mar. 2012; Accepted: $13^{\text {th }}$ Jan. 2013.

\section{ABSTRACT}

Background: Humans have three different types of hair. Hair growth is a complex process that requires a rich supply of oxygen and nutrients provided by the capillaries that supply the active base of the hair.

Objective: To present abnormal growth of hair post prolong immobilization with plaster of Paris.

Material and methods: This report is a case series study carried out in Mosul teaching hospital, during the period between (30 Jan 1999 - 30 Sep 2011). The total number of patients treated for developmental dysplasia of the hip (DDH) were 213 patients treated by open reduction), immobilized by plaster of Paris for a period (8 - 16 weeks). Age ranged between (12-48 months) with mean (24.6 months). Females were 164 $(77 \%)$ and $49(23 \%)$ were males.

Results: Patients followed post operatively, abnormal hair growth at the lower limbs was noticed, and hair changes were disappeared completely within 4-6 months.

Conclusion: Hypertrichosis is transient, physicians should be aware of its benign nature as it relates to cast immobilization.

Keywords: Hypertrichosis, lower limbs, DDH, plaster of Paris.

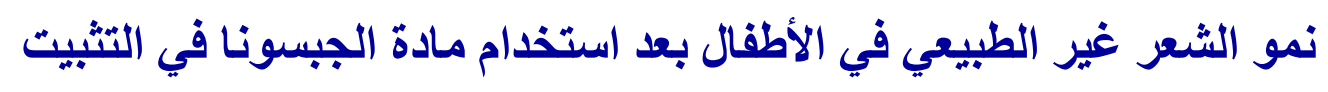

الخلفية: للإنسان ثلاثة أنواع من الثعر. نمو الثعر عملية معقدة وتتطلب تزويد عالي بالأوكسجين والمواد الغذائية من خلال

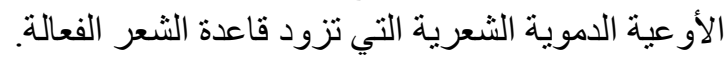

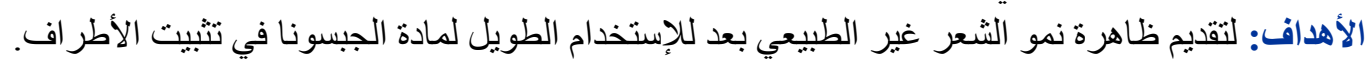

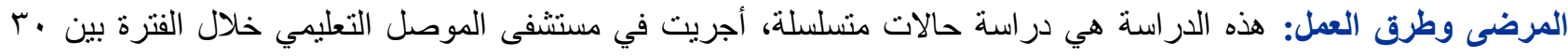

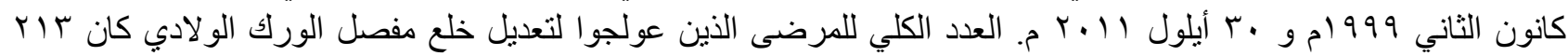

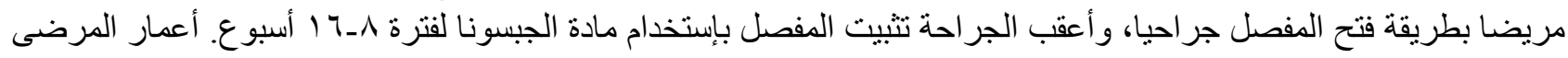

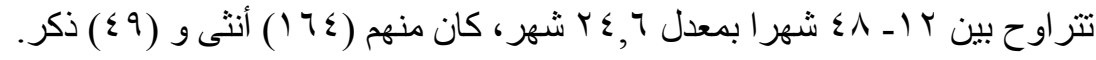

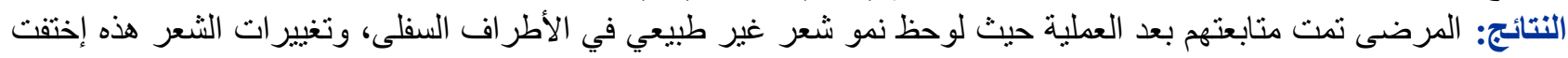

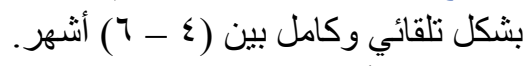
الاستنتاج: أن نمو الثعر غير الطبيعي بعد إستخدام مادة الجبسونا هو مؤقت وهو غير مدعاة لقلق الأطباء كونه حميد في طبيعته ومؤقت ومرتبط بإستخدام مادة الجبسونا.

$\mathrm{H}$ umans have three different types of hair: Lanugo, the fine, unpigmented hair that covers nearly the entire body of a fetus, Vellus hair, the short, downy, "peach fuzz" body hair (also unpigmented) that grows in most places on the human body. Terminal hair, the fully developed hair, which is generally longer, coarser, thicker, and darker than vellus hair, and often is found in regions such as the axillary, male beard, and pubic (1). Unlike other mammals, hair growth and loss is random and not seasonal or cyclic. Hair growth passes through different stages, Catagen, 
Telogen, Anagen (2). Hair growth is a complex process that requires a rich supply of oxygen and nutrients provided by the capillaries that supply the active base of the hair. Hypertrichosis may be generalized or localized, congenital or acquired. Hypertrichosis refers to increased vellus hair and is unrelated to androgen excess ${ }^{(2)}$. This is in contrast to hirsutism, localized hypertrichosis has been reported following topical use of hydrocortisone and in mentally retarded patients who repeatedly bite or scratch their hands or arms following chronic irritation, friction, or inflammation ${ }^{(2)}$. Cutaneous hyperemia resulting from infection or trauma may result in the growth of long and coarse hair at the affected sites. The sudden appearance of excessive hair growth in a localized body area following a fracture or cast application has rarely been reported ${ }^{(3)}$. Hair grows from small organs (follicles) located within the complex microenvironment of the skin which has multiple layers of tissue ${ }^{(4)}$.

The aim of study is to present abnormal hair growth in children immobilized with plaster of Paris for long times.

\section{PATIENT, METHODS AND RESULTS}

In department of orthopedic, at Aljumhoori teaching hospital, 213 patients who were operated upon for treatment of developmental dysplasia of the hip (DDH) by open reduction, between (30 Jan 1999 - 30 Sep 2011), their ages ranged between (12-48 months), mean (24.63 months); 49 males (23\%), 164 female (77\%). Operations done through modified Somerville surgical procedure for treating developmental dysplasia of the hip (DDH) by open reduction followed by derotation femoral osteotomy or pelvic osteotomy, immobilization by plaster of Paris for a period (8-16 weeks) depending on surgical finding and follow up, (Fig. 1).

After removal of plaster of Paris, dark, coarse, long hair was noted; the hair growth was particularly profuse near the knee and it differs in both length and texture from that of the normal leg, (Fig. 2).

In cases of bilateral DDH, where both sides operated on at different times, with immobilization applied for both hips in full spica, when plaster of Paris was removed after 16 weeks, profuse, dark, coarse, long hair on both lower limbs was noted. The hair growth did not differ between the right and left lower limbs, but was abnormal when compared with the upper limbs (Fig. 3).

Three months later resolution of the hypertrichosis started (Fig. 4). Complete spontaneous resolution of hypertrichosis was noted 6 - 12 months after cast removal.

Abnormal coarse hair varies in consistency, and distributed according to the laterality. In case of unilateral hip spica hair changes appear clearer in comparison with normal lower limb. In case of both lower limbs the hair appeared more profuse (Fig. 5 \& 6).

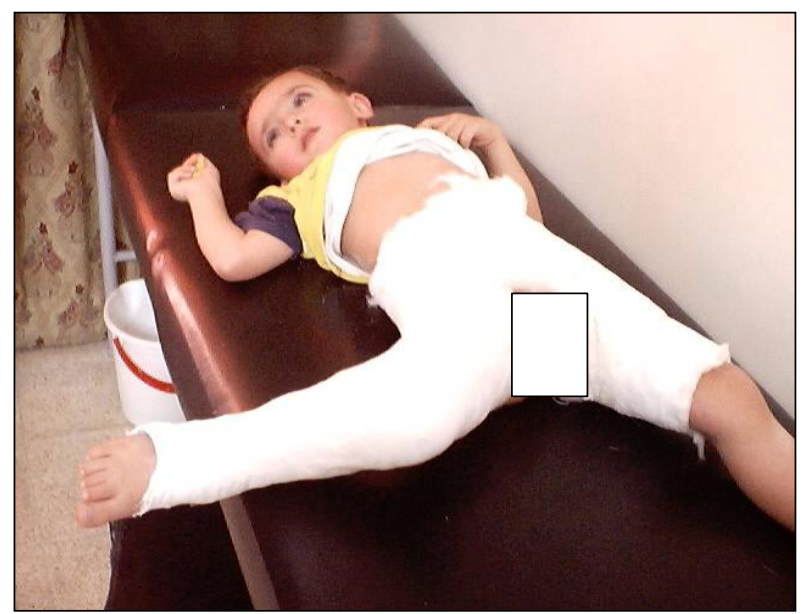

Figure 1. Photograph of child with right hip dislocation, immobilization with plaster of Paris.

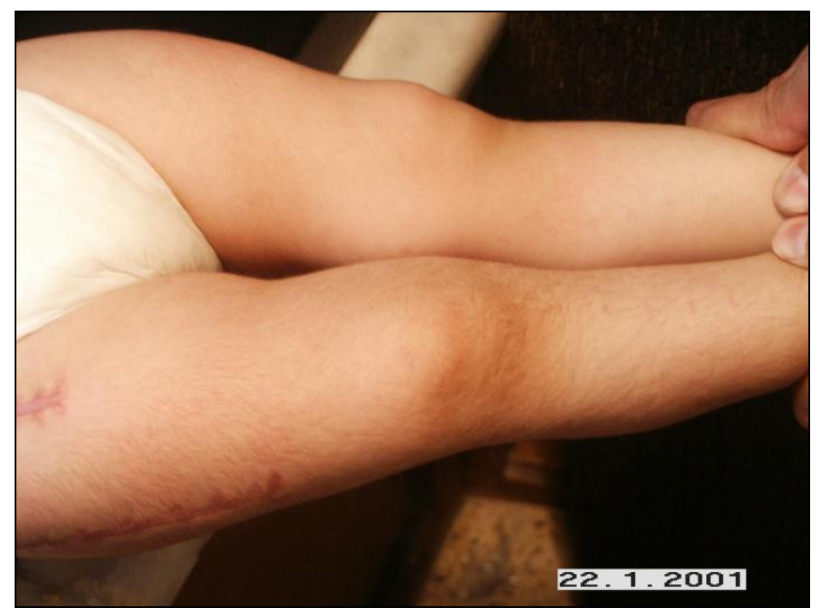

Figure 2. Photograph for female child post management for the right hip coarse skin hair appears in the picture while absent hair on the left lower limb. 


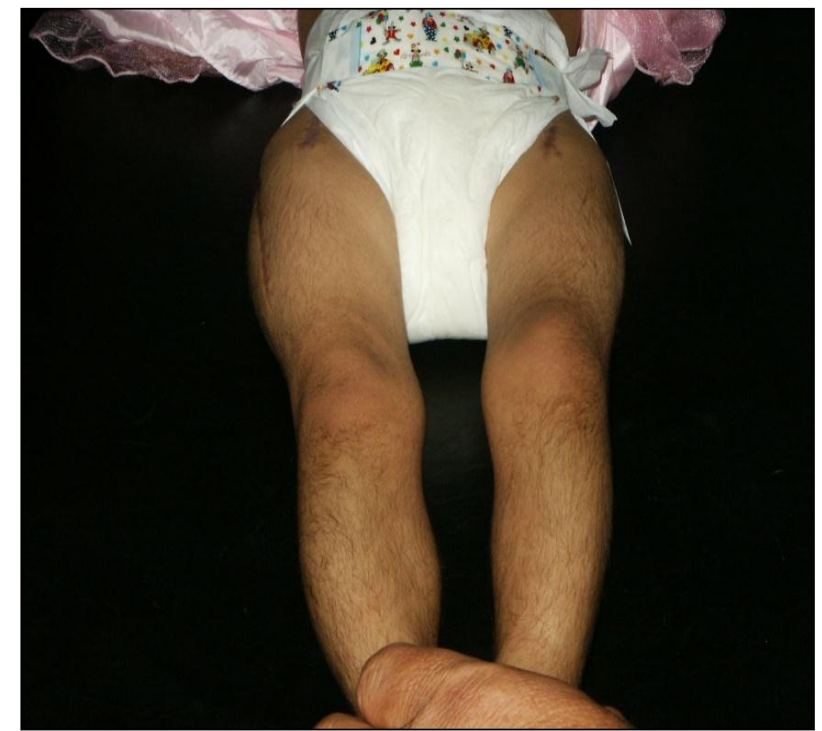

Figure 3. Photography of both lower limbs with clear evidence of abnormal profuse hair growth for female child.

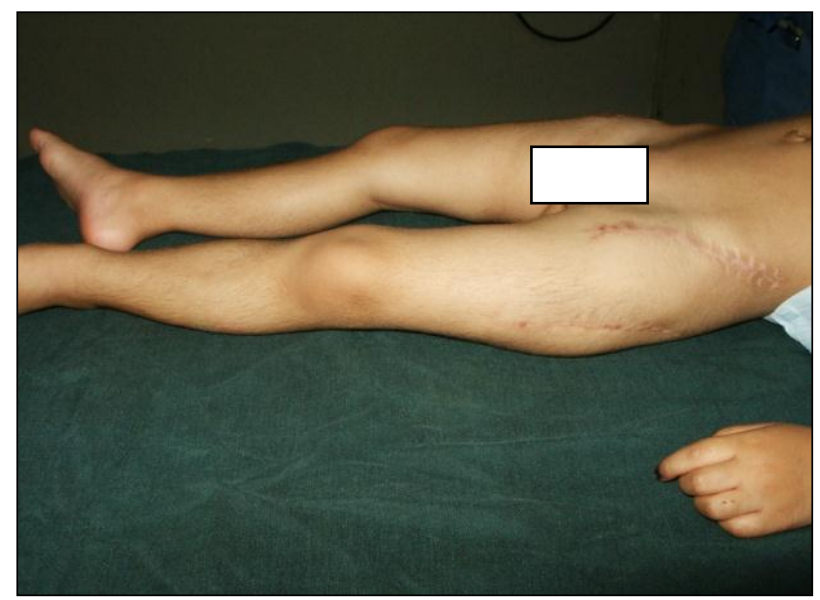

Figure 4. Photograph for female patient 5 months later, hair started to change to normal.

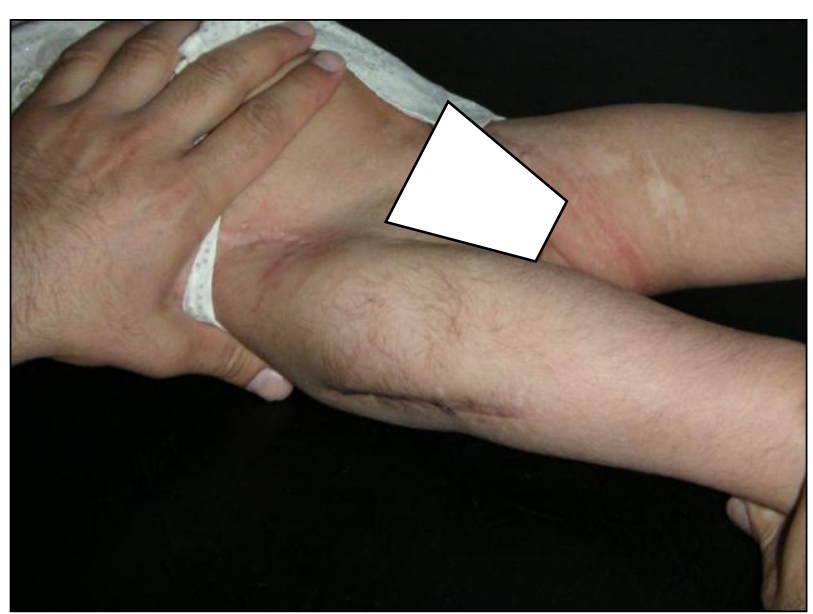

Figure 5. Photograph for female with profuse distribution of the hair look more around the site of surgery, genitalia was involved also.

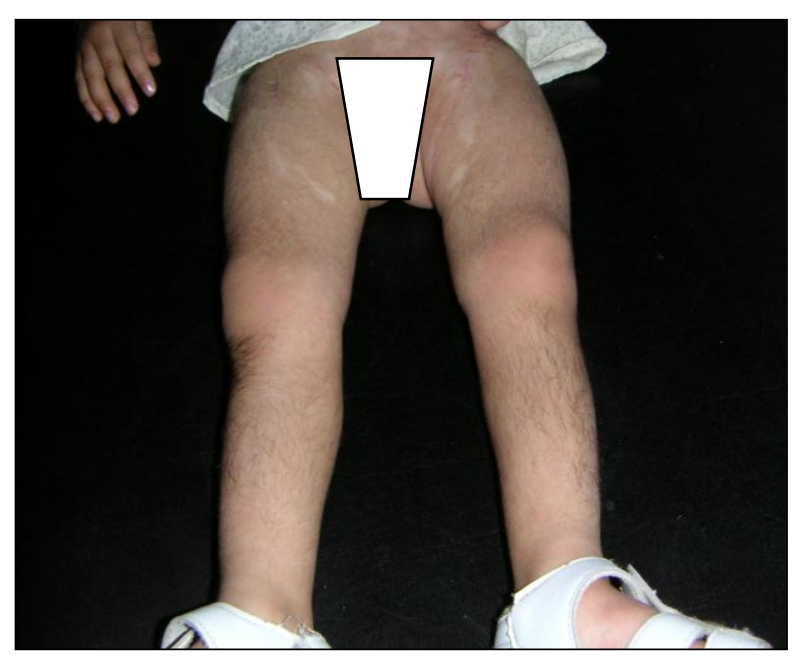

Figure 6. Photograph for same female patient with profuse distribution of the hair with extension around both legs.

\section{DISCUSSION}

Our study revealed clear evidence of abnormal excessive growth of hair along lower limbs. This hairy change was clearly observed after treatment with spica immobilization. Probably local heat produced, affects the vascularity of the skin which leads to hair growth in an abnormal manner. Similar to our findings ${ }^{(3)}$, Dorothea mentioned in his study, common type of circular plaster cast was applied, and over the next 7 weeks there were cast changes. Following removal of the cast a localized area of long, coarse dark hair extended almost to the knuckles on the dorsal aspect of the hand; the hair differed in both texture and pattern of growth from that over the right wrist ${ }^{(3)}$. Because of its transient nature, aggressive investigations are definitely not indicated.

Heat and cutaneous hyperemia are acknowledged by dermatologists as definite stimulants of the hair follicle. Although regional blood flow to a long bone is increased following a fracture, cutaneous hyperemia is definitely a transient phenomenon and may be responsible for the transient hypertrichosis. However because this condition is transitory reaction, hormonal studies to date have not been confirmatory. A suggestion that hypertrichosis may be related to reflex sympathetic dystrophy is also not substantiated in the orthopedic literature ${ }^{(4-10)}$.

Gunilla ${ }^{(11)}$ explained that, mediators of paracrine and autocrine interactions trigger intracellular signals that are transmitted to the nucleus, where the activation of specific transcription factors 
establish and propagate proper epithelialmesenchymal interactions help in growth of hair in the skin.

In conclusion, the hypertrichosis follow prolong immobilization is transient, physicians should be aware of its benign nature as it relates to cast immobilization.

\section{REFERENCES}

1. Types of hair. Human Physiology/ Integumentary System [Online].Wikibook/main page. [Cited 2011]. Available from:URL:http://en.wikibooks.org/wiki/ Human_ Physiology/Integumentary_System.

2. The Biology of Hair Phases of Hair Growth \& Hair Shape [online]. From Heather Brannon Updated December 03, 2006. [Cited 2011]. Available from: URL:http://About.com.dermatology.

3. Dorothea B. Localized hirsutism following Colles' fracture. Can Med Assoc 1983; 128 (15): 368-370.

4. Alexander K C L, Gerhard N K. Localized Acquired Hypertrichosis Associated With Fracture And Cast Application. Journal of the National Medical Association 1989; 81:65 - 67.

5. Harkey M R. Anatomy and physiology of hair. Forensic Science International 1993 (63); 1-3:9-18.
[Cited 2011]. Available from: URL: http://www. sciencedirect.com.

6. Amanda M M O. Hypertrichosis and hirsutism. N Z F P 2005; 32 (2):106-109.

7. Akcakus M, Koklu E, Kurtoglu S, Koklu S, Keskin M and Buyukkayhan D. Perinatal /neonatal case presentation. Neonatal hypertrichosis in an infant of a diabetic mother with congenital hypothyroidism. Journal of Perinatology [serial on line]. 2006. [Cited 2011]. Available from: URL: http://www.nature.com/jp.

8. Baumeister F A M, Schwarz H P, Stengel-Rutkowski S. Childhood hypertrichosis: diagnosis and Management. Current Topic. Archives of Disease in Childhood 1995; 72: 457-459.

9. 9.Ulrike B, Stephen A, Jerry $S$, et al. European Consensus on the evaluation of women presenting with excessive hair growth. Clinical report. Eur J Dermatol 2009; 19 (6): 597-602.

10. Kathryn A M, Chang R J, David A E, et al. Evaluation and Treatment of Hirsutism in Premenopausal Women. The Journal of Clinical Endocrinology \& Metabolism 2008; (93), 4: 1105-1120.

11. Gunilla $T$, Anna $S$, Anna-Carin $H$, Leif C. Cyclic Expression of Lhx2 Regulates Hair Formation. PLoS Genetics org 2010; (6)4:1-16. [Cited 2011]. Available from: URL: http://www.plosgenetics. 